\title{
Black Box - A GSM Based Flood Alert and Rescue System
}

\author{
Sanal Kumar T S ${ }^{1}$, Reshma M A , Athira A S $^{3}$, Ardra Ramachandran ${ }^{4}$ \\ Assistant Professor, Computer Science, Universal Engineering College, Thrissur, India ${ }^{1}$ \\ Student, Computer Science, Universal Engineering College, Thrissur, India ${ }^{2,3,4}$
}

\begin{abstract}
The occurrence of the natural disaster is a big lose for human life and property. Here we introduce a embedded system using ATmega 328 called black box which have water level sensor that helps in the rescue mission. If any disaster like flood occurs sensor senses the water level, whenever it exceeds the threshold value the black box system gets $\mathrm{ON}$ and further the alert message is send to the authority. The system is provided with a mobile charger ,light and a hooter. Black box system is powered with solar panel. This project is used for real time purpose for saving lives and property. A GSM wireless communication technology is used in the system thus no network issues arise.
\end{abstract}

Keywords: Embedded System, Microcontroller ATmega328, GSM, Data Modem, Flood, Rescue

\section{INTRODUCTION}

Flood is a natural disaster that is caused due to the accumulation of excessive water in a region. This is often an outcome of heavy rain fall from $8^{\text {th }}$ august 2018 severe floods affected Kerala, due to unusual high rainfall during the monsoon season. It was the worst flood in Kerala in nearly a century over. Today there exist quite a number of flood detecting algorithms, developed by researches, only a small number of flood monitoring systems are currently used in our country. Apart from that, it becomes difficult to fix the location of the people who are trapped inside the houses and the buildings and would normally take a lot of time in rescue mission to be completely successful. Thus, the overall effective flood prediction and the rescue becomes difficult. There is no available system that allows people to know about the flood danger level of the location in real-time. Here we introduce a design of an automated flood detecting and alerting system that is capable of collecting data regarding the present location from installed sites continuously, and making it readily available to the experts in the flood rescuing team or to the fixed authority thereby rescuing operation becomes more easier and it helps in reducing the loss of life which is the dangerous after effect of flood.

\section{RELATED WORKS}

$\mathrm{In}^{[1]}$ This system is used to detect and control the water level of water tank. The system first senses the amount of water in the tank by water level detector and then adjust the state of the water pump. If the water is empty in the tank then it is level 1 and if water is full in the tank ten it is at level 9. The water pump automatically turn on and start filling the if water level is 1 and stop filling the water when level reaches 9 . Between 2 and 8 there is no change. The system consist of water level sensor , digital logic processing unit and seven segmented display unit.

$\mathrm{In}^{[2]}$ An IOT based flood monitoring and artificial neural network based flood prediction is designed with the aim of enhancing scalability and reliability of flood management system. The main aim of the system is to monitor the humidity, temperature, pressure, rainfall, river water level and to find their temporal correlative information for flood prediction analysis. The IOT is deployed for the data connection from the sensor and communication over Wi-Fi and ANN approach is used or the analysis of the data in flood prediction.

$\mathrm{In}^{[3]}$ This system consist of two components :hardware components and software components. Hardware components are micro controller, communication device and a sensor. The software components involves a data base, application programming interface web based and mobile based. It use an IOT based approach. The system will monitor the potential drainage usually occurs flooding and share the information in real time to people nearby. For this the data collected by the water level sensor will store in the database before it sends to the last output which is the end user. We create API for the manipulation of data such as for access the data that need to be proceeds and also transfer the data if need cross platform within a different domain .

$\mathrm{In}^{[4]}$ The system contains an embedded data acquisition module that can be placed in a remote area in order to collect environmental data such as amount of rain fall, water fall and image periodically. The collected data are then send to the server on a database and processed to determine early warning if flood in the area based on historical data. A web application and mobile application have been designed and developed for user to view measured data. Moreover the mobile application is capable of receiving a push notification of warning message of potential flooding. 
$\mathrm{In}^{[5]}$ Kerala state has an average annual precipitation of about $3000 \mathrm{~mm}$. Kerala has experienced an abnormally high rainfall from $1^{\text {st }}$ June 2018 to 19 August 2018 in contrast to an excepted $1649.5 \mathrm{~mm}$ of rainfall that is $42 \%$ above the normal. To the end of July the first onset of flood occurs. Water was released from several dams due to heavy rainfall. Reservoirs were almost at their FRL. The huge run off from the reservoir in a short period of three days was beyond the carrying capacity of most of the rivers in Kerala resulting over bank flow from most of the rivers . the worst affected districts were Wayanad, Idukki, Ernakulum, Alappuzha and Pathanamthitta. The recommendations provided to avoid flood damages is to make efficient discharge of flood run off from reservoirs provide proper chananels by considering hydrology, ecology etc based on scientific engineering inputs.

$\mathrm{In}^{[6]}$ in this we are proposing to incorporate a disaster mode in to all mobile phones whenever a traditional network will be damaged or out of service, the mobile phones will automatically switch to and start to operate in disaster mode and this will allow the conservation of the phone battery as long as possible, sending disaster messages or placing voice calls to the concerned people. Users will able to update their status and establish their location quickly to facilitate rescue even if the infrastructure is damaged. Then the entire process can be done by using an application which will be triggered once the necessity for D2D communication is decided, that is when the traditional or legacy cellular network will be out of service for a certain interval which may be called a bacon interval which will be 10 MS or any multiple of it.

$\mathrm{In}^{[7]}$ This system addresses the issue of disaster early warning monitoring and management in systematic manner and offers a general approach to management solution. From the view point of control theory. It depicts the disaster early warning, monitoring and management as an information chain which has five links: disaster model bank link, disaster monitoring network link, disaster transmission channel, disaster analysis and management link and decision making command link. The five links constitute an information loop, with disaster data being collected processed through the chain and control information being fed back to the different links

$\mathrm{In}^{[8]}$ Flash flood is a disaster that requires fast detection in order to prevent loss of life. We proposed a low cost system, which is developed on android phone and Arduino board. This system is about to measure water level by an echolocation method, collect information by its sensors, and transmit information to the server via mobile networks or long range Wi-Fi. Low level features such as color, are analyzed at the phone as a decision trigger for network connection in order to reduce network cost. Other high level features are extracted at the server in order to determine whether it is a flash flood

$\mathrm{In}^{[9]}$ The system consist of three sensors, a GSM module and mobile phone. The working is based on the sensor detection .Level 1 sensor is at the lowest part.When it receives a signal the sensor would send 1 to the MCU,so it identifies the alert trigger. MCU sends AT command of flood at alert level to GSM module. At level 2 which is flood at warning level and three flood at danger level. The system software s developed with c compiler program .It has two segments the input segment which controls data from the sensors and the output segment that control the data send to GSM.

$\mathrm{In}^{[10]}$ The system proposes a microcontroller based e-emergency system with wireless ad-hoc network. This system includes e-nurse card positioning reader and wireless module. The radar and ad-hoc network technique are integrated for position and communication. The system can be established easily anywhere and anytime without any infrastructure .In the real test, not only the monitor sender but also the small smart phones in anywhere can monitor the real time safety information of the rescue team workers that is heartbeat, breathe and position

In ${ }^{[11]}$ the system is made up of MCU and GSM modem and it uses infrared sensors to detect dangers. Once there is any disaster it will directly convey the alarm news in short message or telephone at managers mobile phone

In ${ }^{[12]}$ here flood alert will be send to the central control office or vehicles accessing the network. It consist of sensor nodes and sink .Each sensor node comprises of magnetic sensors, a micro processor a radio and a battery .Sensor monitors sense the environment and send the result to the sink via radio signal . the signal comprises a radio a more powerful processor , and a GPS receiver. The sink processes the data received from the sensor . the processed results are either stored at the sink or send to a central repository. Sink is powered by batteries

$\mathrm{In}^{[13]}$ This system development involves various phases starting with the first phase of data collection. If deals with the physical deployment of sensing device in the river banks and implementation of a effective localization scheme depending in the situation and environment. The flow path of the river, past records of water flow and future prediction of the root of the river influence the placement of the wireless sensors. The sensors form clusters to communicate with the local base station. The data send from the sensors are aggregated to the data process center. Level 2 is communication at the district level and level 3 is central monitoring system at the headquarters. Data analysis then take place at the outside research center to do high risk flood analysis

$\mathrm{In}^{[14]}$ The system consists of M number of wireless sensor nodes (WSNs) deployed at several locations along the river .Six nodes taken together constitute a cluster. For each cluster, a cluster head is selected. Each node of the cluster is reading one of the river characteristics and sending normalized value to a selected cluster head. The cluster head processes the obtained data by neural network program. At each cluster head, a single neural network is implemented. Based on the previous training from the numerically generated data, the neural networks are capable of predicting the flood conditions at monitoring zone. The cluster head finally sends. At the central monitoring station, data 
management systems are analyzing the wireless sensor network node data from each cluster head node. A cluster consisting of six WSN nodes is shown in the model and cluster heads are shown by black color. The cluster heads are also WSNs but they collect the data from all the other WSNs and simulate them by ANN. The result of the simulation is four output vectors which are sent to the central monitoring station for comparative analysis and decision making. The input vectors after simulation produces one of the four output vectors as Alarming, Low Flood, High Flood and Very High Flood. This output vector is transmitted to the Central Monitoring Station via local BTSs.

In $\left[{ }^{15]}\right.$ This flood warning system composes of remote stations, application/database server, and users applications. Each remote station is an embedded system for collecting environmental data, which are amount of rainfall, water level, and image of the environment During the design stage of the remote station, in addition to connecting the rain gauge, an ultrasonic sensor, and a camera; one of the requirements is to have an embedded system in a remote area and use mobile cellular data network to send data to the central server over the Internet without investing on or building an infrastructure. This comes to selecting a suitable embedded system platform. Initially, Arduino platform, which is a microcontroller-based embedded system, was the very first candidate since it is an open platform with convenient development tools and strong community support. However, at the time of designing and researching there were limited choices of GSM modules to be used with Arduino and the costs were high. Besides, resources for implementing Arduino with TCP/IP protocol were limited at that time. Hence, it comes to the conclusion to look into microprocessorbased embedded platform.

$\mathrm{In}^{[16]}$ this pre-flood warning system consists of three main systems; the identification system, the data processing system and the SMS broadcast system. To measure water level, ultrasonic sensor will be installed at a riverbank. Data gathered from the ultrasonic sensor will be sent to a microcontroller that will process the data and analyse the data with reference to past cases. The processed data will be sent to a Global System for Mobile (GSM) modem in the form of SMS to be broadcasted to all logged users and local authorities for evacuation process. The GSM modem will be connected to the nearest cell tower in order to get a list total user registered in that particular area. Thus, SMS notification is sent based on the assumption from the mobility of users. There will be two types of warning; first warning is to alert users on the status of water level and warn users to prepare for evacuation process as flood could possibly happen and the second warning will inform users to immediately avoid the area or go to the nearest evacuation center

$\mathrm{In}^{[17]}$ In the main system, the ultrasonic is an input subsystem which will continuously measuring the water level. This process is controlled by the microcontroller. By the time the water level reached the flood-prone, flood or safe boundaries, the ultrasonic will send the data coding which provides current condition. After that the microcontroller will command the GSM modem to send a short message to the client. This system is equipped with a calibration system to register the client number which will receive SMS alerts prone to flooding. Calibration system is also required to set the water boundaries that are prone to flooding limit, flooding and safe limits. All communication between the client system is done by using SMS in accordance with the predetermined SMS delivery format.

$\mathrm{In}^{[18]}$ The system adopts the WebGIS structure based on B/S (Browser/Server), realizes GIS and the Internet technology organic integration, which may have the more widespread scope of the visit and simple to operate and more efficient computing load balancing. Through the analysis of user needs, the system design as follows: (1) Taking ESRI ArcIMS9.0 and SQL Server as background supporting system, and carrying on the system integration based on web technology through the interdependence of spatial data and attribute data. (2) Based on the currently popular component technology, applying ArcXML and Javascript language, designing and developing map browsing, autoalarm, reporting output, and other functions. (3) Applying WebGIS authorized security management, setting for the mapping service access to different users in the network. According to the user authority, providing different WebGIS browser interfaces in client side, namely simple HTML Viewer interface and powerful Java Viewer interface of Java Applet. The data obtained from Hydrological station are analyzed and compared with the basic information of the Lake area through the Internet, then carrying on auto-alarm for those hydrological sites whose water levels exceed the warning water levelThe long-distance monitoring and auto-alarm system of disaster situation besides has the automatic alarm function, but also has the function of map browsing, SQL query, geographic analysis, data management, system setup and so on. Below are introduced the realization of automatic alarm and SQL query.

$\operatorname{In}^{[19]}$ This is mainly intended to determine rainfall and atmospheric data, as well as monitor solutions, to improve flood monitoring and early alert system. The purpose of the first core component is to assess rainfall-discharge and rainfall distribution data, which has an impact on flood disaster in the Wangthong watershed, through the IFAS and the WRF models, respectively. Rainfall data, used to evaluate rainfall-discharge and rainfall distribution, is derived from the Tropical Rainfall Measuring Mission (TRMM) and atmospheric data in the GRIB (Gridded Binary) format, between the year 2005 and 2010. A comparison between the amount of water discharged and the duration of the water discharged returning period will indicate the severity of the flooding stage. This method is used to estimate threshold discharge value for warning. The purpose of the second core component is to assess the inundated areas. The pre- 
Vol. 8, Issue 3, March 2019

programming is written using MATLAB and database as a backend system to identify the inundated areas for management of flood disaster.

$\mathrm{In}^{[20]}$ system that is not dependent on mobile towers for alert message broadcasting, a less power consuming system, works well even in absence of internet, broadcasts messages directly to civilians and so the delay is avoided and free from complex calculations. The reason behind this work is mainly because of the huge loss Chennai faced in 2015 . The DAM water filling plant consists of level sensor and flow sensor for monitoring level and speed of flow of water. If the level is low, medium or high(exceeds threshold) then microcontroller automatically sends the information about the water level to server.

\section{DESIGN METHODOLOGY}

\section{A. System Flowchart}

The system receives the water level from the float level sensor as an input to the microcontroller system. Microcontroller is programmed with a threshold value of water level and by comparing it with the value given by the float sensor. When the water level reaches beyond the threshold value, an alert signal is provided to the user automatically and the location will be send to the authority using GSM. Otherwise the user is able to press the button provided on the system manually for getting the help. Then the authority can provide immediate rescue to the isolated people there by the life of many individuals are saved.The flowchart of the system is shown in fig 1

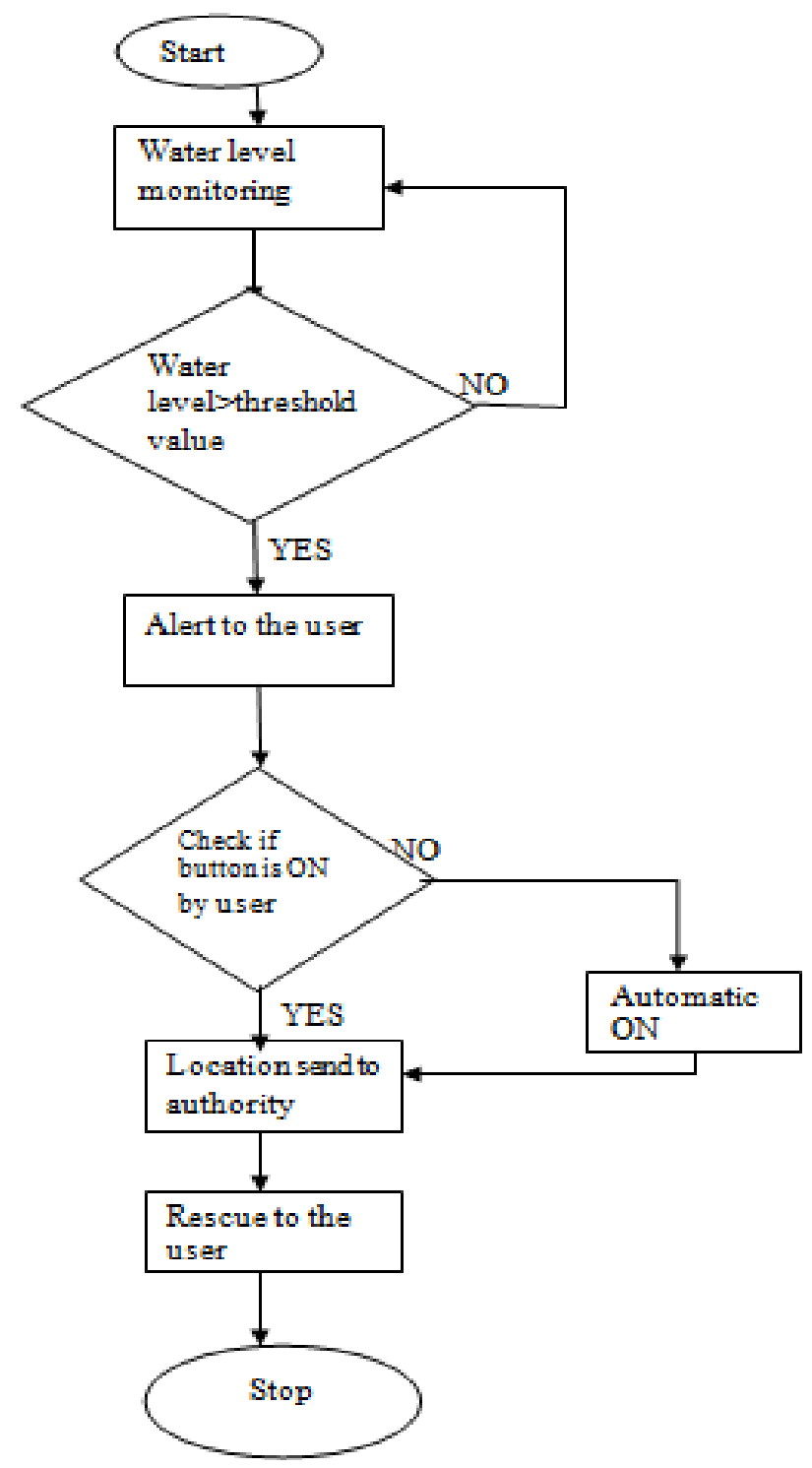

Fig 1:flowchart of the system 


\section{B. Block Diagram}

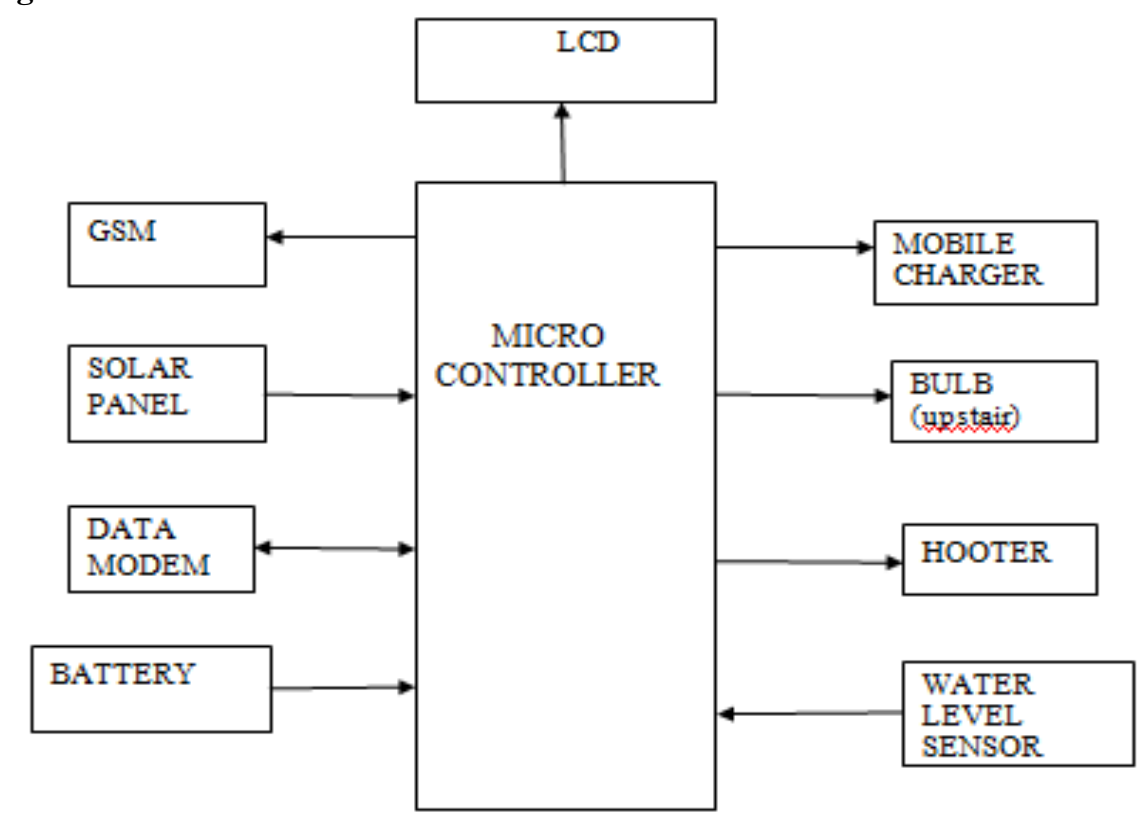

Fig 2:User module

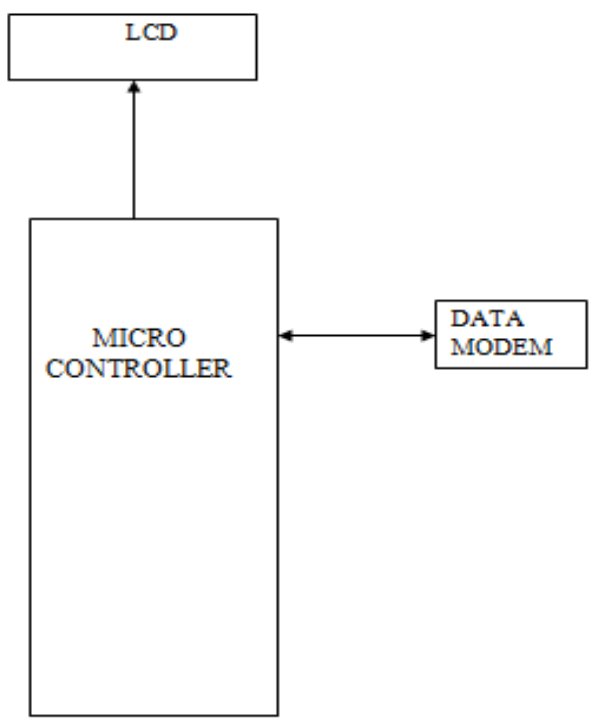

Fig 3:Control module

The black box system is an embedded system with two sections, one section in user side for interacting with the user(shown in fig 2) and another section in the authority side (shown in fig 3)to track the location of the user and to provide the service. The embedded system consist of ATMEGA 328 micro controller, which is a32 bit microcontroller. A GSM module, battery charger, solar panel, alert system, button, LCD, data modem and also simple transistor based water level indicator is attached with it. The working is based on sensors water level detection. Whenever a flood happens the water level will start to increase. The water level indicator which detects the water rise and give alert to the user when level reaches beyond the threshold value. The user can press the button to send the location to the authority. If he or she not able to press the button the black box system automatically send the location using GSM module. So the authority can track the isolated location and can provide rescue. Also a data modem which is attached in the system is responsible for sending the alert message to nearby control station 


\section{SEQUENCE DIAGRAM}

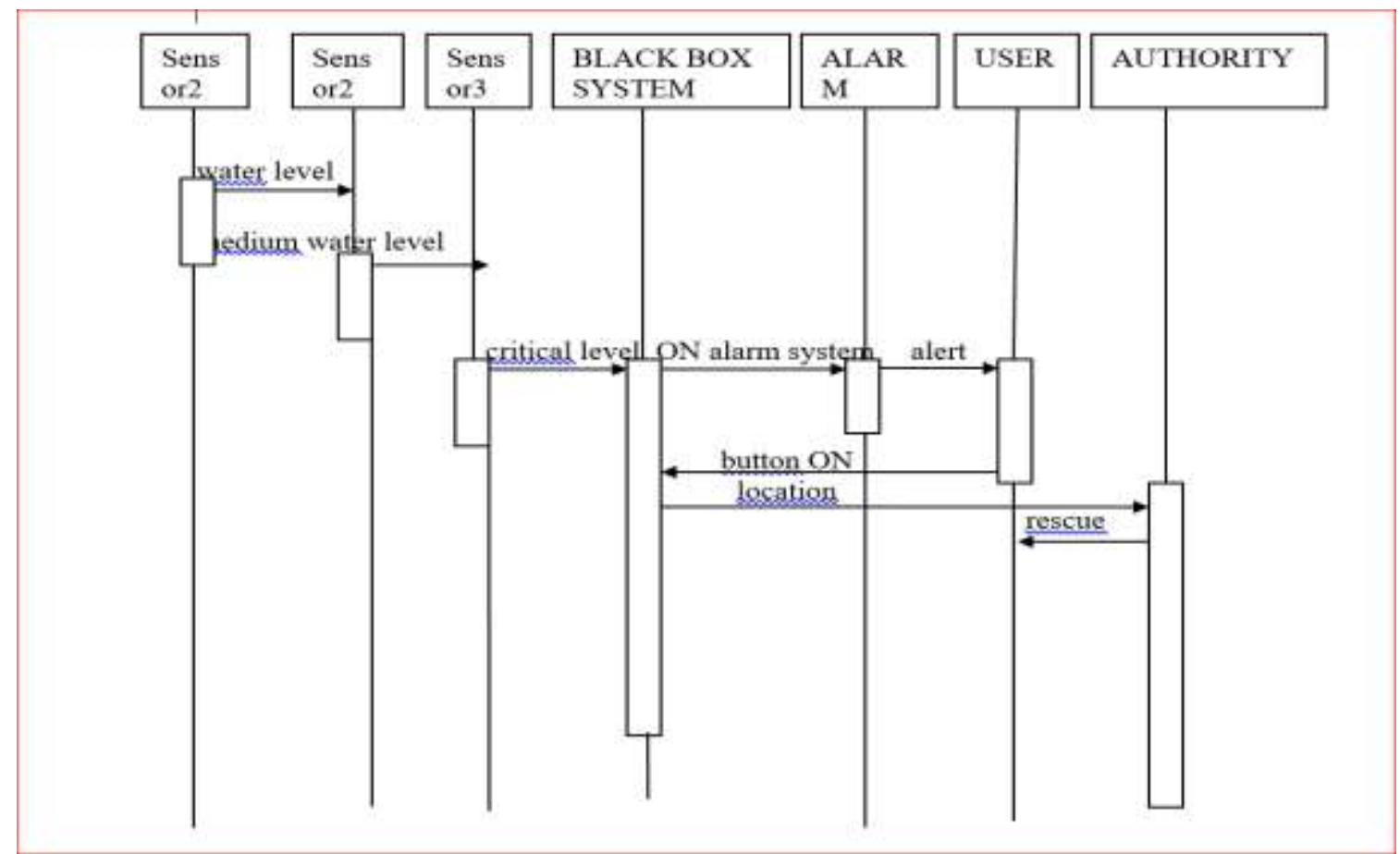

Fig 4:sequence diagram

\section{SYSTEM OVERVIEW}

A. Water Level Sensing

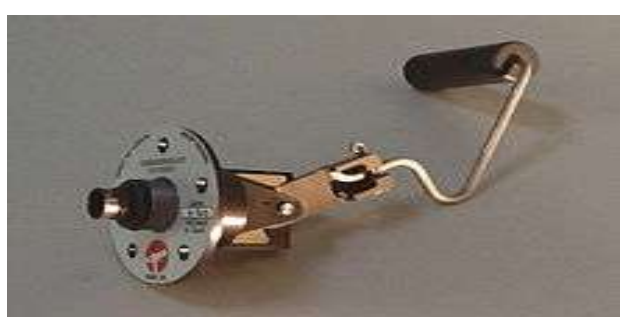

Fig 5:float level sensor

The float level sensors(shown in fig 5) are used to detect the current level of water. it is provided with float balls, are spherical, cylindrical, oblong or similarly shaped objects, made from either rigid or flexible material, that are buoyant in water and other liquids. whenever the water starts to rise from the ground level the float balls rises with it.

B. Microcontroller

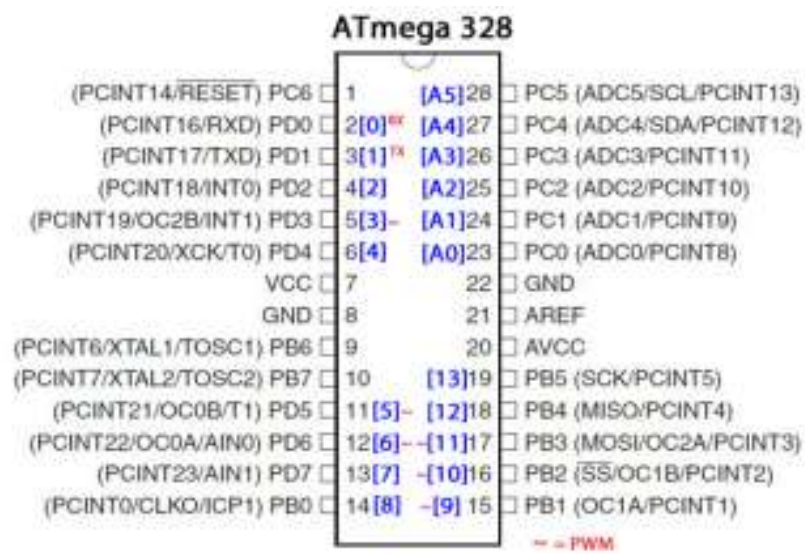

Fig 6:pin out of Atmega 328 
Vol. 8, Issue 3, March 2019

The microcontroller used here is ATmega 328 which is provided with 28 pins(pinout of Atmega 328 is shown in fig 6). TheATmega328 is a low-power CMOS 8-bit microcontroller based on the AVR enhanced RISC architecture. By executing powerful instructions in a single clock cycle, the ATmega328 achieves throughputs close to 1MIPS per MHz. This empowers system designer to optimize the device for power consumption versus processing speed. Microcontroller is programmed with a threshold value of water level and comparing it with the value given by the float sensor.

C . Sending location using GSM module

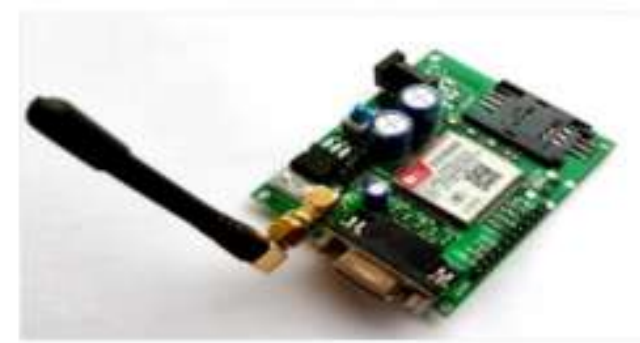

Fig 7:GSM module

GSM is a cellular network (shown in fig 7) which means that cell phones connect to it by searching for cells in the immediate vicinity. Using this GSM module the user is able to send the current location to the authority automatically or manually by pressing the button provided .It helps the authority in the rescue mission fastly.

D. Data Modem

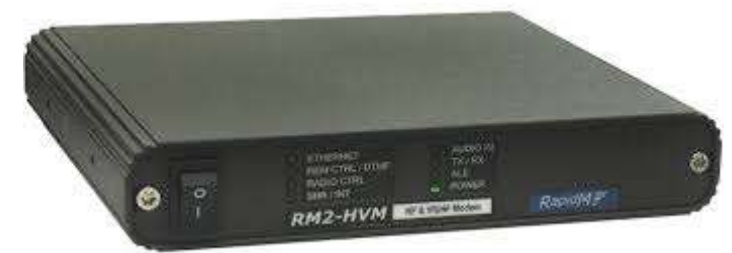

Fig 7 :Radio modem

Radio modems(shown in fig 7) encode, transmit, receive and decode serial data using radio waves. They connect to serial ports on devices such as video cameras and data acquisition systems, and send signals to and receive signals from other radio modems.

V. ARCHITECTURE

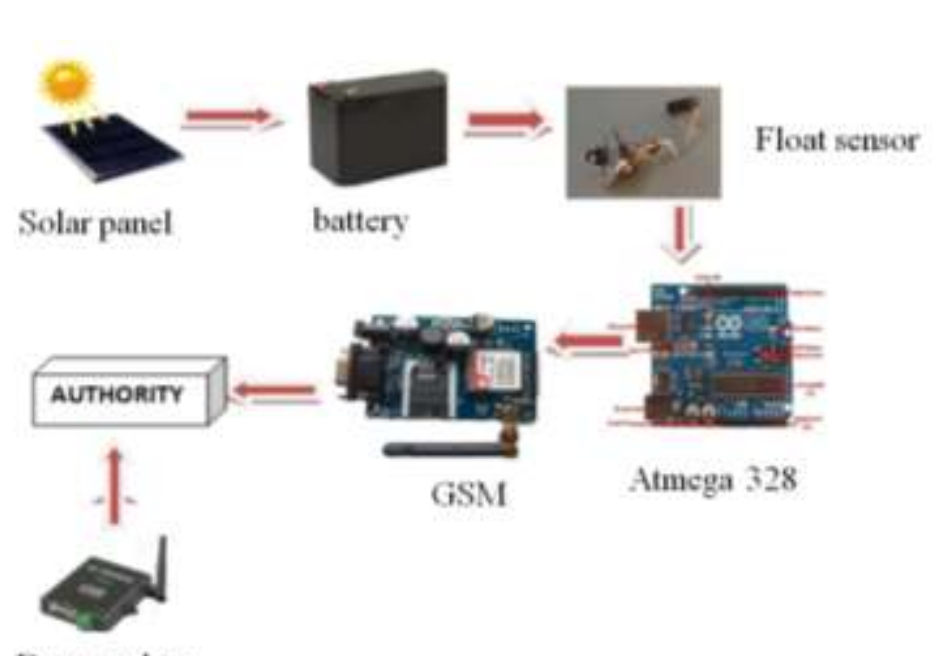

Data modem

Fig 8:system architecture 
Vol. 8, Issue 3, March 2019

\section{RESULTS}

This test(shown in table 1) is to determine the average time it takes for the system to sense the flood water level. Quick response is the primary points of the efficiency of the design prototype. Sending the message as soon as the water level is sensed is the most crucial part of the reliability of the design.

Table 1:average time test

\begin{tabular}{|c|c|c|}
\hline Trials & $\begin{array}{c}\text { Sensing Time } \\
\text { (seconds) }\end{array}$ & $\begin{array}{c}\text { Sending Time } \\
\text { (seconds) }\end{array}$ \\
\hline 1 & 1.23 & 2.09 \\
\hline 2 & 1.07 & 1.89 \\
\hline 3 & 0.97 & 1.68 \\
\hline 4 & 1.35 & 2.15 \\
\hline 5 & 1.04 & 1.78 \\
\hline Average & 1.13 & 1.86 \\
\hline
\end{tabular}

This shows that our system taking sensing time of 1.13 seconds and 1.86 seconds for sending the sensing value. The time it takes to sense and send the sensed value are lesser than we expect. So time lagging can be avoid. Our system tries to avoid the problems created due to the natural disaster like flood. Our System is to give immediate rescue to the isolated people during flood. People were isolated in many places and they were unable to send their location to the authority because of loss of inter connectivity and power. Our system will send the isolated location and alert message to the authority through GSM and radio modem.

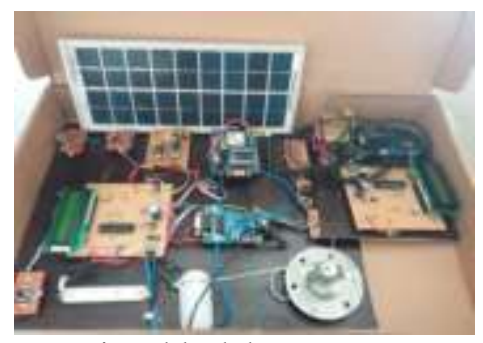

Fig 9:black box system

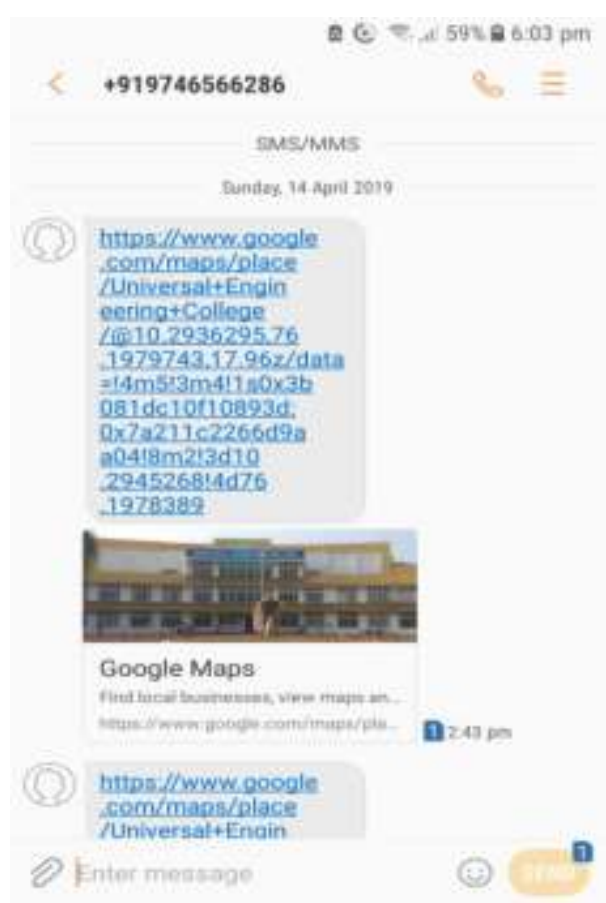

Fig 10: Received location pointing message. 


\section{International Journal of Advanced Research in Computer and Communication Engineering}

Vol. 8, Issue 3, March 2019

VII.

\section{CONCLUSION}

Black box system(complete system shown in fig 9) is trying to avoid the problems created due to the natural disasters. The latest issue that Kerala faced was flood. People were isolated in many places and they were unable to send their location to the authority because of loss of inter connectivity and power. By installing the product in the house, we can easily send the location to the authority even when there is no network connection. The solar panel provided helps to charge the mobile phones so that we are able to use the mobile phones even when its battery dead due to loss of electricity. Maximum protection and safety of the people is main aim of black box system and while testing the performance of sensing time and sending time is $1.13 \mathrm{sec}$ and $1.86 \mathrm{sec}$. The implementation of the project controls the consequences caused due to the natural calamities like flood. Black box system ensures the maximum safety of mankind and infrastructure.

\section{REFERENCES}

[1]. Basha and D.Rus ,Design of Early warning Flood detection systems for developing countries, Proceedings of the conference on Information and Communication technology and development. December 2007.

[2]. M. Haraguchi and U. Lall, Flood risks and impacts: A case study of Thailands floods in 2011 and research questions for supply chain decision making, International Journal of Disaster Risk Reduction, 2014.

[3]. S. Hussin, M. N. Ismail, and H. Sofian, Intelligent Flood Information System via SMS (IFIS), Proc. of the 6th International Conference on Ubiquitous Information Management and Communication (ICUIMC12), Kuala Lumpur, Malaysia, 2012.

[4]. S. Keoduangsine and R. Goodwin, "An appropriate flood warning system in the context of developing countries," International Journal of Innovation, Management and Technology, vol. 3, pp. 213-216, 2012.

[5]. B. Ramamurthy, S. Bhargavi, R. ShashiKumar, Development of a Low-Cost GSM SMS-based Humidity Remote Monitoring and Controlling Systerm for Industrial Applications, IJACSA, Vol 1, No 4, 2010

[6]. Liu Xiaosheng and Chen Youliang, Research of Geographic Information System of Flood Prevention and Control in Poyang Lake Area, The CHINA Association for Science and Technology, vol. 1, Nov. 2004, pp. 462-466.

[7]. P. Limlahapun and H. Fukui, Flood Monitoring and Early Warning System: The Integration of Inundated Areas Extraction Tool, The Society of Instrument and Control Engineers (SICE) Journal of Control, Measurement, and System Integration (JCMSI), Vol. 3, No. 6, pp. 476-482, 2010.

[8]. Victor Seal et al, A simple flood forecasting scheme using wireless sensor networks. International Journal of Ad hoc, Sensor \&Ubiquitous Computing (IJASUC) Vol.3, No.1, February 2012

[9]. Basha, Elizabeth A., SaiRavela, and Daniela Rus. "Model-based monitoring for early warning flood detection." Proceedings of the 6th ACM conference on Embedded network sensor systems. ACM, 5-7 November 2008.

[10]. Danny Hughes, Phil Greenwood, Gordon Blair, Geoff Coulson, Florian Pappenberger, Paul Smith and Keith Beven. An Intelligent and Adaptable Grid-based Flood Monitoring and Warning System (DRAFT).UK eScience All Hands Meeting 5th, 2006

[11]. Fateen et al, Pre-flood warning system based on user mobility. ARPN Journal of Engineering and Applied Sciences , VOL. 10, NO. 23, DECEMBER 2015 ISSN 1819-6608

[12]. Beza N. Getu Nasser A. Hamad Hussain A. Attia "Remote Controlling of an Agricultural Pump System Based on the Dual Tone MultiFrequency (DTMF) Technique" Journal of Engineering Science and Technology (JESTECH) vol. 10 no. 10 pp. $1261-1274$ 2015

[13]. S. K. Subramaniam V. R. Ganapathy S. Subramonian A. H. Hamidon "Flood level indicator and risk warning system for remote location monitoring using flood observatory system" WSEAS Transactions on Systems and Control vol. 5 no. 3 pp. 153-163 2010.

[14]. K. Auynirundronkool N. Chen C. Peng C. Yang J. Gong C. Silapathong "Flood detection and mapping of the Thailand Central plain using RADARSAT and MODIS under a sensor web environment" International Journal of Applied Earth Observation and Geoinformation vol. 14 no. 1 pp. $245-2552012$.

[15]. United Nations Global Survey of Early Warning Systems Pre-print version released at the Third International Conference on Early Warning Bonn 27-29 March 2006 IEEE Xplore

[16]. Basha, D. and Rus, D. Design of Early Warning Flood Detection System for developing countries. Proceeding of the conference on Information and Communication Technologies and Development, Bonsalove, India. Pp 1-10, 2007

[17]. Semantic Scholar "SMS The Creation of Personal Global Text Messaging" in Hillebrand \&amp; Trosby Wiley 2008

[18]. W. Massagram V.M. Lubecke A. Host-Madsen and O. Boric-Lubecke "Assessment of Heart Rate Variability and Respiratory Sinus Arrhythmia via Doppler Radar " IEEE Trans. Microwave Theory and Tech. vol. 57 no. 10 pp. 2542-2549 Oct. 2009.

[19]. Lin Y.-H. Chen B.-F. Wu "A real-time multiple-vehicle detection and tracking system with prior occlusion detection and resolution and prior queue detection and resolution" Pattern Recognition 2006. ICPR 2006. 18th International Conference on vol. 1 pp. $828-8312006$.

[20]. Pak E. Rho J. Chang M. Kim "Demand-Driven Curriculum for Embedded System Software in Korea" Proceedings of the 2005 Workshop on Embedded Systems Education pp. 11-15 September 222005.

[21]. Lin Y.-H. Chen B.-F. Wu "A real-time multiple-vehicle detection and tracking system with prior occlusion detection and resolution and prior queue detection and resolution" Pattern Recognition 2006. ICPR 2006. 18th International Conference on vol. 1 pp. 828-831 2006. 